\title{
Lamination of the Lateral Geniculate Nucleus of Catarrhine Primates
}

\author{
Alexandra A. de Sousa ${ }^{a}$ Chet C. Sherwood ${ }^{b}$ Patrick R. Hof ${ }^{c}$ Karl Zilles ${ }^{d, e}$ \\ ${ }^{a}$ Department of Life Sciences, University of Coimbra, Coimbra, Portugal; ${ }^{b}$ Department of Anthropology, Center for \\ the Advanced Study of Hominid Paleobiology, The George Washington University, Washington, D.C., and \\ 'Fishberg Department of Neuroscience and Friedman Brain Institute, Icahn School of Medicine at Mount Sinai, \\ New York, N.Y., USA; ${ }^{d}$ Institute of Medicine, Research Center Jülich, Jülich, and ${ }^{\mathrm{e}} \mathrm{C}$. and O. Vogt Institute of \\ Brain Research, Heinrich Heine University, Düsseldorf, Germany
}

\section{Key Words}

Phylogeny · Catarrhines · Primates · Vision · Lateral

geniculate nucleus

\begin{abstract}
The lateral geniculate nucleus (LGN) of catarrhine primates - with the exception of gibbons - is typically described as a 6-layered structure, comprised of 2 ventral magnocellular layers, and 4 dorsal parvocellular layers. The parvocellular layers of the LGN are involved in color vision. Therefore, it is hypothesized that a 6-layered LGN is a shared-derived trait among catarrhines. This might suggest that in gibbons the lack of further subdivisions of the parvocellular layers is a recent change, and could be related to specializations of visual information processing in this taxon. To address these hypotheses, the lamination of the LGN was investigated in a range of catarrhine species, including several taxa not previously described, and the evolution of the LGN was reconstructed using phylogenetic information. The findings indicate that while all catarrhine species have 4 parvocellular leaflets, two main patterns of LGN parvocellular lamination occur: 2 undivided parvocellular layers in some species, and 4 parvocellular leaflets (with occasional subleaflets) in other species. LGN size was not found to be related to lamination
\end{abstract}

pattern. Both patterns were found to occur in divergent clades, which is suggestive of homoplasy within the catarrhines in LGN morphology.

\section{Introduction}

Catarrhines, the group of primates comprising humans, apes and Old World monkeys, are characterized by shared features of the visual system, including the sharedderived feature of routine trichromacy. The lateral geniculate nucleus (LGN), i.e. the dorsal subdivision, is a part of the visual thalamus that regulates the transmission of information from both eyes to the cerebral cortex, and occurs in each hemisphere of the brain (fig. 1). Given its appearance in histological sections stained for cell bodies, the LGN is considered '6-layered', but this description of its structure has led to some confusion about its organization. In spite of the relative homogeneity of visual function within the catarrhines, it has been noted that the LGN is not always '6-layered'. However, there is currently no basis for concluding that species-specific variation in the number of LGN layers has any consequences for vision [Erwin et al., 1999]. This paper focuses on the vari-

\section{KARGER}

E-Mail karger@karger.com

www.karger.com/bbe
(C) 2013 S. Karger AG, Basel

0006-8977/13/0812-0093\$38.00/0 


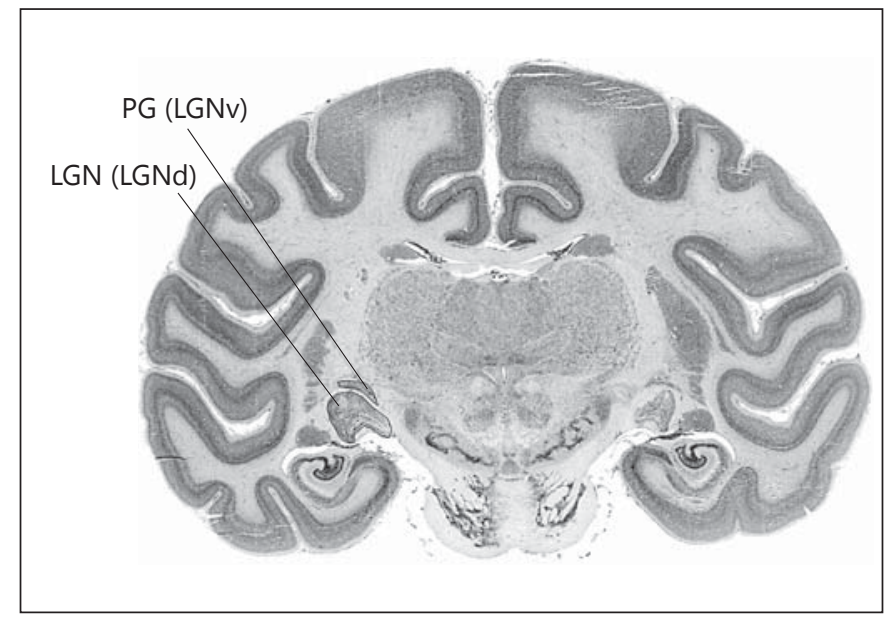

Fig. 1. Coronal section through brain of Macaca fascicularis showing location of LGN and PG (pregeniculate nucleus). LGNd = Dorsal lateral geniculate nucleus; $\mathrm{LGNv}=$ ventral LGN.

ants in catarrhine LGN laminar pattern as observed in sections stained for cell bodies, relative to LGN and brain size and phylogeny.

The LGN is well known for its role in transmitting signals along the retinogeniculocortical pathway, although retinal afferents are only a minority of its inputs, which also include the primary visual cortex and the thalamic reticular nucleus [Saalmann and Kastner, 2011]. In primates, the LGN is comprised of easily recognizable parvocellular $(\mathrm{P})$ and magnocellular $(\mathrm{M})$ layers and less conspicuous koniocellular (K) layers, each of which belongs to distinct pathways processing different aspects of visual input.

Each pathway is comprised, in catarrhines, of a distinct group of nerve fibers originating from retinal ganglion cells and terminating in the LGN. The magnocellular pathway originates in the large, sensitive parasol ganglion cells of the retina, which primarily get inputs from rods, and which synapse in the magnocellular, i.e. large-celled, layers of the LGN, and then project to layer 4Ca of cortical area V1. The magnocellular pathway carries high-contrast visual information, including information about motion. The parvocellular pathway originates in the small, numerous midget ganglion cells of the retina, which primarily get inputs from cones (see below), and which synapse on the parvocellular, i.e. small-celled, layers of the LGN, which then project to layer $4 \mathrm{C} \beta$ of V1 [Leventhal et al., 1981; Rodiek, 1988]. The parvocellular pathway carries information about color and fine structure.
Magnocellular and parvocellular pathway organization is maintained in $\mathrm{V} 1$ and its primary target, $\mathrm{V} 2$, as the P-I (P interblob), P-B (P blob), and M streams [DeYoe and Van Essen, 1988]. Early visual areas V1 and V2 have feed-forward projections to higher visual areas, in which visual streams and related functions become more segregated. Areas V3 [Felleman and Van Essen, 1987], V3A [Tootell et al., 1997] and middle temporal (MT) [Albright et al., 1984] are involved in motion detection, and are associated with the M stream [DeYoe et al., 1990]. Area V4, dubbed the 'color center' [Lueck et al., 1989; McKeefry and Zeki, 1997; Zeki, 2004], is associated with the P-B and P-I streams [DeYoe et al., 1994; Van Essen et al., 1992].

More recently, in macaques, koniocellular, i.e. very small-celled, neurons have been distinguished from LGN neurons of the magnocellular and parvocellular pathways on the basis of positive immunohistochemical staining for the a subunit of type II $\mathrm{Ca}^{2+} /$ calmodulin-dependent protein kinase (aCAMKII) [Hendry and Yoshioka, 1994; Yoshioka and Hendry, 1995], the calcium-binding protein calbindin [Goodchild and Martin, 1998; Jones and Hendry, 1989] and the gamma subunit of protein kinase C [Fukuda et al., 1994]. In fact, the koniocellular neurons in the LGN have been known for quite some time to exist in anthropoids [Chacko, 1948, 1949, 1954, 1955a; Le Gros Clark, 1941a, 1941b; Solnitzky and Harman 1943], and are sometimes referred to as 'interlaminar cells' or as occurring within 'intercalated layers'. The koniocellular layers of catarrhines are presumably homologous to the prominent koniocellular layers of lorises and bushbabies [Kaas et al., 1978]. Koniocellular neurons are distributed in 6 distinct layers in the catarrhine LGN, one located ventral to each magnocellular and parvocellular layer, and additional neurons with the koniocellular neurochemical signature are distributed within the magnocellular and parvocellular layers [Hendry and Reid, 2000; Hendry and Yoshioka, 1994; Yoshioka and Hendry, 1995]. Displaced koniocellular neurons form perpendicular bridges that link koniocellular layers by splitting up parvocellular and magnocellular layers. In macaques, koniocellular LGN axons originating from the ventral LGN layers $\mathrm{K} 1$ and $\mathrm{K} 2$ terminate in V1 layers 1 and $3 \mathrm{~A}$, and those originating from the dorsal LGN layers K3-K6 terminate in layer 3Ba [Casagrande et al., 2007].

The koniocellular and parvocellular laminae belong to two different subsystems in which color information is processed. The ancient subsystem, which also exists in dichromats, is primarily responsible for differentiating 'blue' outputs of short-wavelength-sensitive (S) cones from 'yellow' outputs of the medium- and long-wave- 
length-sensitive (M/L) cones. In this subsystem, small bistratified retinal ganglion cells with large receptive fields draw outputs from $S$ cones and $M / L$ cones, and these outputs are carried to the koniocellular laminae of the LGN [Regan et al., 2001]. The recent subsystem exists only in trichromats, and is primarily responsible for differentiating the green outputs of $\mathrm{M}$ cones from the red outputs of L cones. In this system, midget ganglion cells with small receptive fields carry outputs of $\mathrm{M}$ and $\mathrm{L}$ cones to the parvocellular laminae of the LGN [Regan et al., 2001].

Other pathways, in addition to the magnocellular, parvocellular and koniocellular pathways, also exist. At the level of the retina, at least ten classes of ganglion cells have been distinguished in macaques [Dacey et al., 2003]. It has been shown that there are direct inputs from the LGN to extrastriate visual areas which do not match criteria for inclusion in magnocellular, parvocellular or koniocellular pathways [Sincich et al., 2004].

Often, the LGN of macaques and humans is described in terms of its 6 principal layers (fig. 2), numbered from the ventral aspect closest to the optic tract and pia mater, to the dorsal aspect closest to the optic radiations. The 2 most ventral layers (layers 1 and 2) are magnocellular, being comprised of large, darkly stained cells. The next 4 layers (layers 3-6) are parvocellular and are comprised of medium, more lightly stained cells. This study uses a different nomenclature which was introduced by Kaas and colleagues [1972; 1978] with the intention of recognizing homologous layers across species based on cell type and location. To envision this scheme, consider a generalized mammalian LGN, which is a 3-dimensional structure in which the 'external' part near the border (on all sides) receives contralateral retinal inputs, and the 'internal' part at the core receives ipsilateral retinal inputs [Huberman and Chapman, 2007]. The LGNs of all primates have 2 magnocellular layers [magnocellular external (ME) and magnocellular internal (MI)] and 2 parvocellular layers [parvocellular external (PE) and parvocellular internal (PI)]. Further subdivisions of the parvocellular layers are called 'leaflets'. Thus, parvocellular layers 3-6 are better described as 2 parvocellular layers, that are divided into 4 leaflets, and are 3-dimensionally complex as the leaflet pairs are fused rostrally [Kaas et al., 1978; Malpeli et al., 1996]. To acknowledge this, leaflets are first named according to the layer of which they are a part (PI or PE) and then according to their location [internal leaflet (LI) or external leaflet (LE)]. Sometimes, the leaflets are further subdivided into divisions called subleaflets.

Also easily visible are other layers ventral to the magnocellular layers and dorsal to the axons of optic tract, e.g. in Balado and Franke [1937] and in Kanagasuntheram et al. [1969]. In most publications these have been called the superficial (S) layers [S internal (SI) and S external (SE)] [Kaas et al., 1978], a term which could actually refer to either of two different things [Hendry and Reid, 2000]. Typically, in catarrhines, $S$ layers refer to a subset of the koniocellular layers, with the pair representing the ipsilateral and contralateral retinae [Hendry and Reid, 2000]. However, displaced magnocellular layers at the same location are also called S layers [Hendry and Yoshioka, 1994]. Here, we retain the traditional nomenclature 'S layers' to refer to the ventral layers without acknowledgement of whether they are in fact magnocellular or koniocellular, because making this distinction was beyond the scope of the study, which incorporates reports published before the koniocellular layers were well known.

In primates that have an LGN with 2 parvocellular layers, 1 layer receives retinal input from the ipsilateral eye, and the other receives retinal input from the contralateral eye. When the parvocellular layers are further subdivided into leaflets, the leaflets are interdigitated, such that a leaflet receiving retinal input from the ipsilateral eye is adjacent to a leaflet receiving inputs from the contralateral eye. Therefore, the distinction made by Kaas et al. [1978] between 'layers' and 'leaflets' is important because although in 2-dimensional cross sections macaques appear to have a total of 6 layers, of which 4 are parvocellular and 2 are magnocellular, 3-dimensional modeling of the LGN shows that pairs of parvocellular layers receiving input from the ipsilateral eye are actually continuous with each other [Erwin et al., 1999].

Physiological studies of lamination in macaques have indicated optical specificity across leaflets. Schiller and Malpeli [1978] found that, in rhesus macaques, blue-sensitive cells were found primarily in the ventral-most parvocellular leaflets, $\mathrm{PE}(\mathrm{LI})$ and $\mathrm{PI}(\mathrm{LI})$. However, this early study only considered the parvocellular and magnocellular layers, and did not distinguish the koniocellular layers from these. More recent studies in marmosets [Martin et al., 1997] and macaques [Roy et al., 2009] indicate that in fact neurons carrying signals from the blue-sensitive $S$ cones are predominantly located in the koniocellular layers, whereas neurons carrying signals from the $\mathrm{M}$ and $\mathrm{L}$ cones are segregated in the parvocellular layers. These findings support the aforementioned distinction between ancient koniocellular and recent parvocellular subsystems of color information processing.

The ventral-most parvocellular leaflets $\mathrm{PE}(\mathrm{LI})$ and PI(LI) also have cells that are mostly off-center, whereas the dorsal parvocellular leaflets PE(LE) and PI(LE) are 
mostly on-center [Schiller and Malpeli, 1978]. Central vision is represented in the segment of the LGN having 4 parvocellular leaflets in macaques, whereas peripheral vision is represented in the part with just the 2 undivided layers [Malpeli and Baker, 1975].

The morphology of the LGN varies between primate groups [Kaas and Huerta, 1988; Kaas et al., 1978]. In addition, there have been some reports of variation in LGN laminar pattern within hominoids [Armstrong, 1979; Chacko, 1955a; Kanagasuntheram et al., 1969; Tigges and Tigges, 1987]. Little is known about how these variations in LGN lamination may be related to species-specific adaptations. Although the LGNs of humans and macaques have been well studied, the laminar pattern of other catarrhines requires further documentation, especially for the colobine monkeys, most hylobatid species, orangutans and bonobos.

The function of LGN lamination has been the object of speculation for some time. Famously, Le Gros Clark [1949], upon pointing out that the laminae were paired for each eye, suggested that in the macaque each of the different pairs of laminae received inputs from only one of each of the three classic color receptor types (red, blue and green; Le Gros Clark [1949]). Although this idea has not held up against recorded responses of LGN cells to monochromatic light [De Valois et al., 1958], the precise reason why macaques, humans and most other catarrhines (which are all trichromatic) have parvocellular leaflets, and why other closely related taxa do not, remains unclear. An hypothesis proposed by Kaas et al. $[1972,1978]$ is that leaflets are related to the increased parvocellular mass of the LGN; although suggesting that size differences might be of functional relevance, this has not been specifically explored.

Here, LGN laminar pattern of catarrhines was considered for the first time in relationship to allometric scaling and phylogeny. The aim of this study was to determine the number of LGN parvocellular leaflets in catarrhine species for which the number is unknown and to provide an outgroup to better understand variation in LGN structure among hominoids. A key goal was to determine whether the laminar patterns found in humans and macaques are in fact homologous. These data were used to explore the possible evolutionary origins of different LGN laminar patterns in the catarrhines. First, the lamination of the LGN was examined in respect to LGN size. Second, the phylogenetic polarity of the observed differences was examined on a phylogenetic tree.

\section{Materials and Methods}

\section{Specimens and Tissue Preparation}

Observations and measurements were made on coronal and sagittal histological sections from adult specimens of a total of 46 brains representing 20 catarrhine species. In order to accumulate a large and diverse sample, specimens in the study came from several different collections: the Zilles and Stephan comparative neuroanatomy collections at the $\mathrm{C} \& \mathrm{O}$ Vogt Institute of Brain Research in Düsseldorf, Germany, the Yakovlev-Haleem and Welker collections at the National Museum of Health and Medicine and the Great Ape Aging Project at the George Washington University, Wash., D.C. and the Icahn School of Medicine at Mount Sinai, New York, N.Y., USA.

The brains from the Zilles collection were immersion-fixed with either $4 \%$ formaldehyde or Bodian's solution within a few hours after death, embedded in paraffin and serially-sectioned along the coronal plane at a thickness of $20 \mu \mathrm{m}$ (except for one chimpanzee brain, which was horizontally sectioned at a thickness of $15 \mu \mathrm{m}$ ), and stained for cell bodies based on the Gallyas procedure [Gallyas, 1971], using silver according to the technique described by Merker [1983]. The brains from the Stephan collection were perfused in situ with Bouin's fluid through the carotid arteries after the blood had been washed out with physiological saline, embedded in paraffin and serially-sectioned along the coronal plane at a thickness of $20 \mu \mathrm{m}$ and Nissl-stained using cresyl violet. The Pan troglodytes brains from the Yakovlev-Haleem collection were sagittally sectioned at a thickness of $35 \mu \mathrm{m}$, and separate alternating series were stained for Nissl and for myelin. The brains from the Great Ape Aging Project were immersion-fixed in 10\% neutral-buffered formalin. Left occipital lobe and parieto-occipital lobe blocks were cryoprotected by immersion with increasing concentrations of sucrose solutions up to $30 \%$, frozen on dry ice, and serially sectioned on a microtome at a thickness $40 \mu \mathrm{m}$, and then Nissl-stained with cresyl violet. For further details about the sections, see online supplementary table 1 (for all online suppl. materials, see www.karger.com/doi/10.1159/000346495). Because multiple collections were used to include as large a sample as possible, it is prudent to keep methodological considerations in mind as the tissue preparation techniques varied across collections, which may impact on volume measurements [Stephan et al., 1981].

\section{Characterization of Parvocellular Lamination}

For each specimen, sections stained for cell bodies either with silver or cresyl violet were examined. A minimum of one left hemisphere was investigated per species, although both right and left hemispheres were investigated for most specimens (the number of specimens per species is indicated in table 1).

Because the number of layers or leaflets is not constant throughout the anterior-posterior extent of the LGN, the entire span of the LGN was investigated in each specimen to determine the maximum number of distinct parvocellular leaflets in a coronal section. Leaflets were considered distinct if they were separated by a sharp, soma-poor gap. Such interlaminar zones could be distinguished from the LGN representation of the optic disc, which is also a type of gap, although its orientation does not follow the laminar pattern. Often, there was no interlaminar space between magnocellular and parvocellular layers, but these two categories of layers were easily distinguished on the basis of location, staining inten- 
Table 1. LGN parvocellular lamination, species mean brain weights and LGN volumes

\begin{tabular}{|c|c|c|c|c|c|c|c|}
\hline Species & Leaflets & $\mathrm{n}$ & $\begin{array}{l}\text { Brain weight } \\
\mathrm{g}\end{array}$ & $\mathrm{n}$ & $\begin{array}{l}\text { LGN volume } \\
\mathrm{cm}^{3}\end{array}$ & $\mathrm{n}$ & LGN residual \\
\hline Homo sapiens & $\mathrm{Y}$ & 10 & $1,303.7$ & 10 & 0.335 & 10 & -13.35 \\
\hline Pan troglodytes & $\mathrm{Y}$ & 6 & 406.5 & 3 & 0.344 & 3 & 5.12 \\
\hline Pan paniscus & $\mathrm{Y}$ & 2 & 364.5 & 2 & 0.282 & 2 & 0.21 \\
\hline Gorilla gorilla & $\mathrm{Y}$ & 1 & 376.0 & 1 & 0.300 & 1 & 1.64 \\
\hline Pongo pygmaeus & $\mathrm{N}$ & 5 & 384.7 & 3 & 0.259 & 3 & -2.73 \\
\hline Hylobates lar & $\mathrm{N}$ & 2 & 106.0 & 2 & 0.166 & 2 & -0.41 \\
\hline Hylobates muelleri & $\mathrm{N}$ & 1 & 101.8 & 1 & 0.162 & 1 & -0.60 \\
\hline Symphalangus syndactylus & $\mathrm{N}$ & 1 & 138.7 & 1 & NA & & NA \\
\hline Cercopithecus ascanius & $\mathrm{Y}$ & 1 & 61.5 & 1 & 0.147 & 1 & 1.03 \\
\hline Cercopithecus mitis & $\mathrm{Y}$ & 2 & 73.3 & 2 & 0.167 & 2 & 2.04 \\
\hline Erythrocebus patas & $\mathrm{Y}$ & 1 & 94.2 & 1 & 0.267 & 1 & 10.45 \\
\hline Lophocebus albigena & $\mathrm{Y}$ & 1 & 110.5 & 1 & 0.182 & 1 & 0.88 \\
\hline Macaca fascicularis & $\mathrm{Y}$ & 1 & 57.6 & 1 & 0.092 & 1 & -4.13 \\
\hline Macaca mulatta & $\mathrm{Y}$ & 1 & 78.0 & 1 & 0.158 & 1 & 0.75 \\
\hline Miopithecus talapoin & $\mathrm{Y}$ & 1 & 41.1 & 1 & 0.109 & 1 & -0.72 \\
\hline Papio anubis & $\mathrm{Y}$ & 1 & 206.5 & 2 & 0.395 & 1 & 17.22 \\
\hline Nasalis larvatus & $\mathrm{Y}$ & 1 & 64.3 & 1 & 0.157 & 1 & 1.75 \\
\hline Pygathrix nemaeus & $\mathrm{N}$ & 1 & 69.0 & 1 & 0.115 & 1 & -2.85 \\
\hline Piliocolobus badius & $\mathrm{N}$ & 2 & 76.9 & 2 & 0.128 & 2 & -2.16 \\
\hline Colobus angolensis & $\mathrm{Y}$ & 1 & 74.4 & 1 & 0.103 & 1 & -4.46 \\
\hline
\end{tabular}

$\mathrm{N}=2$ parvocellular layers; $\mathrm{Y}=4$ parvocellular leaflets (may include subleaflets).

sity, and cell size. Note that potential 'hidden layers' may exist (see Discussion); however, because these are not known in catarrhines and were not visible in the available material, they could not be accounted for in this study.

\section{Estimation of Volumes}

Volume measurements were taken for the dorsal part of the LGN complex, which is laminated and is most often just called the LGN, but is also known as the dorsal lateral geniculate nucleus, dorsal lateral geniculate body or corpus geniculatus lateralis dorsalis. The unlaminated anterior LGN, known as the ventral LGN or pregeniculate nucleus, was excluded (fig. 1).

LGN residual volumes were calculated to determine whether change in LGN morphology might be better attributed to changes in LGN volume relative to brain volume. The residual values were calculated from the equation

LGN residual volume $=$

(observed LGN volume - expected LGN volume) $\times 100$

in which the expected LGN volumes were determined from an ordinary least-squares regression of $\log$ (LGN volume) as a function of $\log$ (brain weight).

All statistical analyses were assessed with an a level of 0.05 . Nonparametric tests for independent samples were performed to determine whether the two groups (2 parvocellular layers and 4 parvocellular leaflets) differed significantly in LGN volume, or LGN volume residual.

\section{Phylogenetic Analysis}

The results were interpreted in an evolutionary context as plotted on a catarrhine phylogenetic tree including the key monophyletic groups discussed here, based on a consensus phylogeny from the 10 kTrees Website [Arnold et al., 2010]. The character plotted on the tree topology was 'parvocellular laminar pattern', and the character states in which it occurs were 'leaflets' where 4 parvocellular leaflets were observed, or 'no leaflets' where only 2 parvocellular layers were observed. The polarity of the character was not determined a priori because it is not clear which, of either of these, would best represent the ancestral catarrhine state. The maximum parsimony reconstruction method was used to trace the evolution of the character.

\section{Results}

\section{Lamination}

The results (table 1) are consistent with earlier observations about LGN lamination (table 2). However, this study presents some clarifications and new data. In the sample, the presence of parvocellular leaflets was not found to vary polymorphically within species. However, in those species in which leaflets occurred, it was found that some (but not all) individuals had further divisions 
Table 2. Previous studies reporting LGN parvocellular lamination in catarrhine species

\begin{tabular}{|c|c|c|c|c|c|}
\hline Species & Leaflets & $\begin{array}{l}\text { Sub- } \\
\text { leaflets }\end{array}$ & $\begin{array}{l}\text { Pro- } \\
\text { jections }\end{array}$ & Number & Publications, first author and year \\
\hline \multicolumn{6}{|l|}{ Hominoidea } \\
\hline Homo sapiens & $\mathrm{Y}$ & $\mathrm{Y}$ & & many & Balado [1937] \\
\hline Pan troglodytes & $\mathrm{Y}$ & $\mathrm{Y}$ & $\mathrm{Y}$ & 1 & Tigges [1977] \\
\hline Gorilla gorilla & $\mathrm{Y}$ & & $\mathrm{N}$ & 1 & Nakagawa [1998] \\
\hline Pongo pygmaeus & $\begin{array}{l}\text { conflicting, } \\
\text { insufficient data }\end{array}$ & & $\mathrm{N}$ & 1 & Balado [1937], Armstrong [1988], Tigges [1987] \\
\hline Hylobates lar & $\mathrm{N}$ & & $\mathrm{Y}$ & 4 & $\begin{array}{l}\text { Chacko [1955a], Armstrong [1979], Tigges [1987], } \\
\text { Kanagasuntheram [1969] }\end{array}$ \\
\hline Hylobates moloch & $\mathrm{N}$ & & $\mathrm{N}$ & 1 & Tigges [1987] \\
\hline Hylobates agilis & $\mathrm{N}$ & & $\mathrm{N}$ & 2 & Kanagasuntheram [1969] \\
\hline Symphalangus syndactylus & $\begin{array}{l}\text { conflicting, } \\
\text { insufficient data }\end{array}$ & & $\mathrm{N}$ & 1 & Kanagasuntheram [1969] \\
\hline \multicolumn{6}{|l|}{ Cercopithecoidea } \\
\hline Cercopithecus ascanius & $\mathrm{Y}$ & & & 1 & Schulz [1967] \\
\hline Cercopithecus aethiops & $\mathrm{Y}$ & $\mathrm{Y}$ & & & Kanagasuntheram [1969] \\
\hline Macaca rhesus & $\mathrm{Y}$ & & $\mathrm{Y}$ & many & Kaas $[1978]$ \\
\hline Macaca fascicularis & $\mathrm{Y}$ & $\mathrm{Y}$ & & & \\
\hline Papio ursinus & $\mathrm{Y}$ & $\mathrm{Y}$ & & & \\
\hline $\begin{array}{l}\text { Mandrillus sphinx } \\
\text { Colobinae }\end{array}$ & Y & $\mathrm{Y}$ & & & Kaas [1972] \\
\hline Piliocolobus badius & $\mathrm{N}$ & & & 1 & Schulz [1967] \\
\hline
\end{tabular}

Retinal projections were studied, for detecting 'hidden layers'. $\mathrm{N}=2$ parvocellular layers; $\mathrm{Y}=4$ parvocellular leaflets (may include subleaflets).

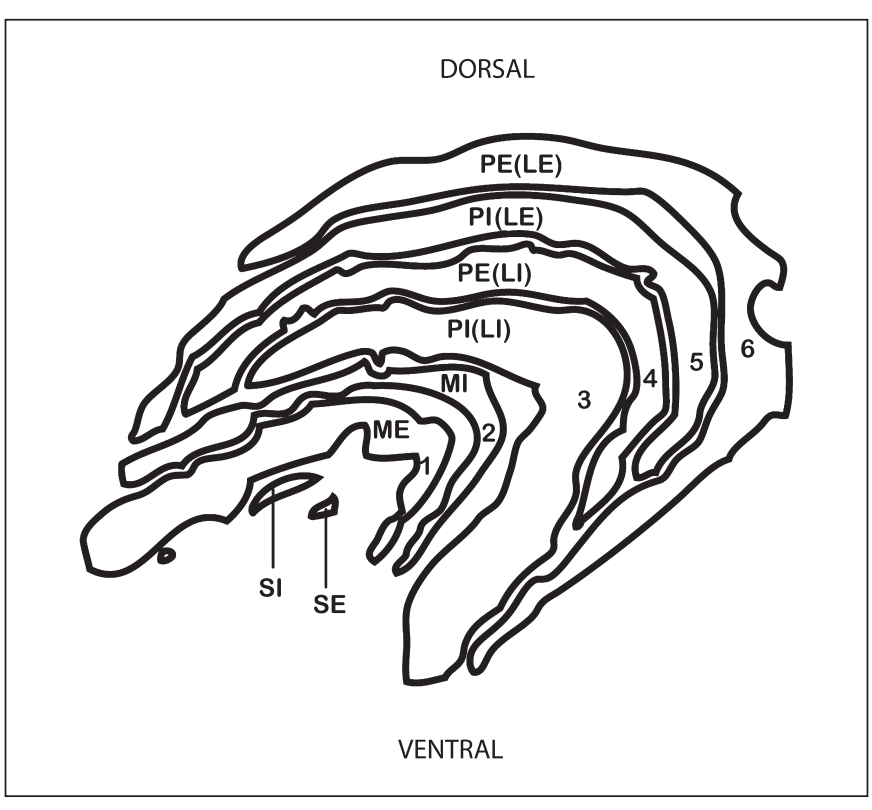

Fig. 2. Schematic diagram showing layers of the LGN in Macaca fascicularis. Traditional (1-6) nomenclature (left) and nomenclature according to Kaas and colleagues [1978] (right) are shown. of the parvocellular layers into subsidiary layers. Therefore, all catarrhine parvocellular laminar patterns fall into either the 'four parvocellular leaflets' or the 'two parvocellular layers' category (table 1 and 2; fig. 3).

It should be noted that the observations made here on orangutans and siamangs add clarification about earlier reports: we found both species to have 2 undivided parvocellular layers. Because studies of LGN lamination have been conflicting or entirely nonexistent for orangutans, bonobos, hylobatids and colobines, specimens belonging to each of these groups are illustrated (fig. 4-8). For $\mathrm{Hy}$ lobates lar, a tracing shows the lamination labeled using both the traditional nomenclature and that of Kaas and colleagues [1978] (fig. 9).

\section{Volumetric Analysis}

LGN volume increases with brain weight across the sample (fig. 10, supplementary table 2). The 2-parvocellular-layer $(n=5)$ and 4-parvocellular-leaflet $(n=14)$ LGN samples overlap in their brain weights (x-axis) and LGN volumes (y-axis). However, larger LGNs tend to 


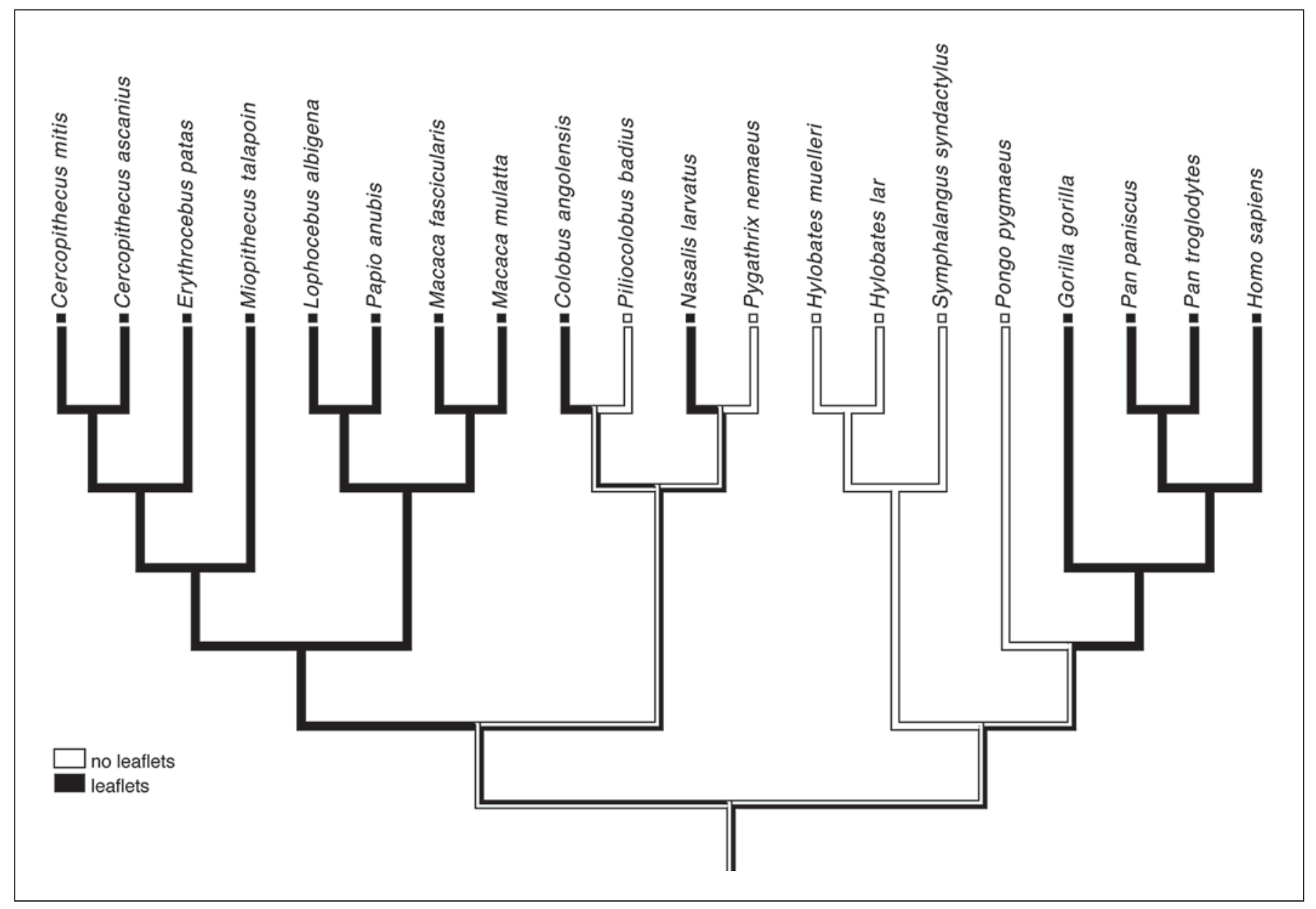

Fig. 3. Maximum parsimony analysis of changes in catarrhine LGN laminar pattern. Changes in the LGN lamination pattern (character state changes) are indicated by bars. Consensus phylogeny from 10kTrees Website [Arnold et al., 2010]. Both the first and second hypotheses of character state evolution require an equal number of (minimum 4) character state changes within the catarrhine clade.

have leaflets, and the 2-parvocellular-layer LGNs all fall below the normal least-squares regression line.

Nonparametric, i.e. Mann-Whitney U tests for two independent samples were conducted to assess whether the leaflet sample had significantly larger LGNs than the noleaflet sample. In addition to comparing LGN volumes, LGN residuals were calculated to determine whether changes in LGN morphology might be better attributed to changes in LGN volume relative to brain weight (table 1). The nonparametric tests for two independent samples failed to detect any significant differences between the leaflet and no-leaflet samples in absolute LGN volume $(\mathrm{p}=0.405 ; \mathrm{U}=44)$. Similarly, no significant difference was detected between these samples in LGN residuals $(\mathrm{p}=0.096 ; \mathrm{U}=53)$.

Catarrhine LGN

\section{Phylogenetics}

For the character 'lamination pattern', a minimum of four character state changes (steps) were required by the consensus phylogenetic tree (fig. 3). There were two equally parsimonious hypotheses of the character state evolution which differ in character polarity: one assumes that the catarrhine ancestral condition is 'leaflets', whereas the other assumes that it is 'no leaflets'. Catarrhine parvocellular patterns are summarized here per monophyletic group. In the hominoid superfamily, both patterns were observed. All four African hominoid species sampled (humans, chimpanzees, bonobos and gorillas) had 4 parvocellular leaflets. Two groups had only 2 parvocellular layers: the orangutans and the hylobatid clade (gibbons and siamangs). Both patterns were also ob- 

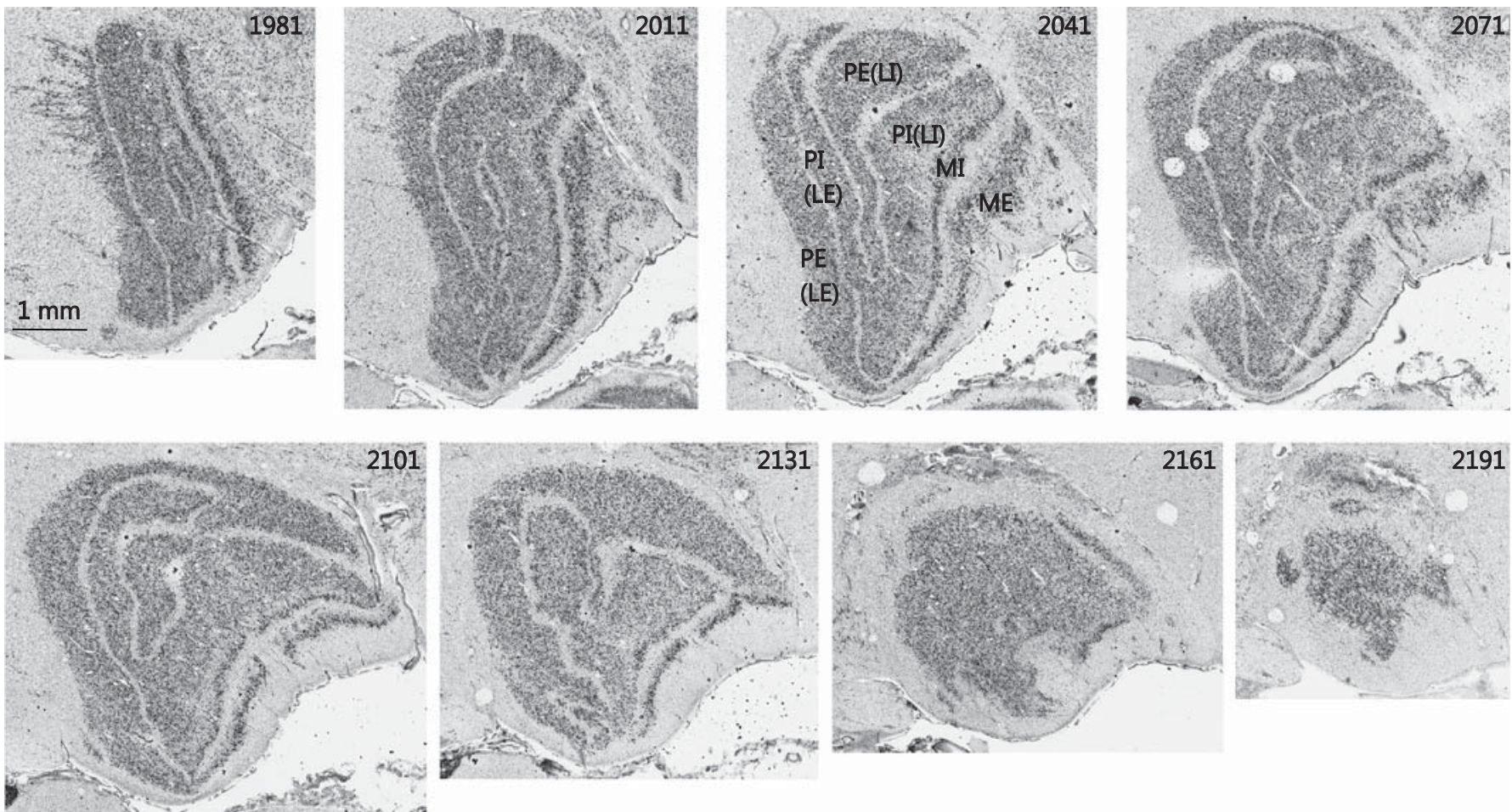

Fig. 4. Coronal sections through left LGN of a juvenile bonobo (Pan paniscus). Sections are numbered from caudal to rostral aspect, as indicated below the images. Two magnocellular layers and 4 parvocellular leaflets are labeled in section 2041 .
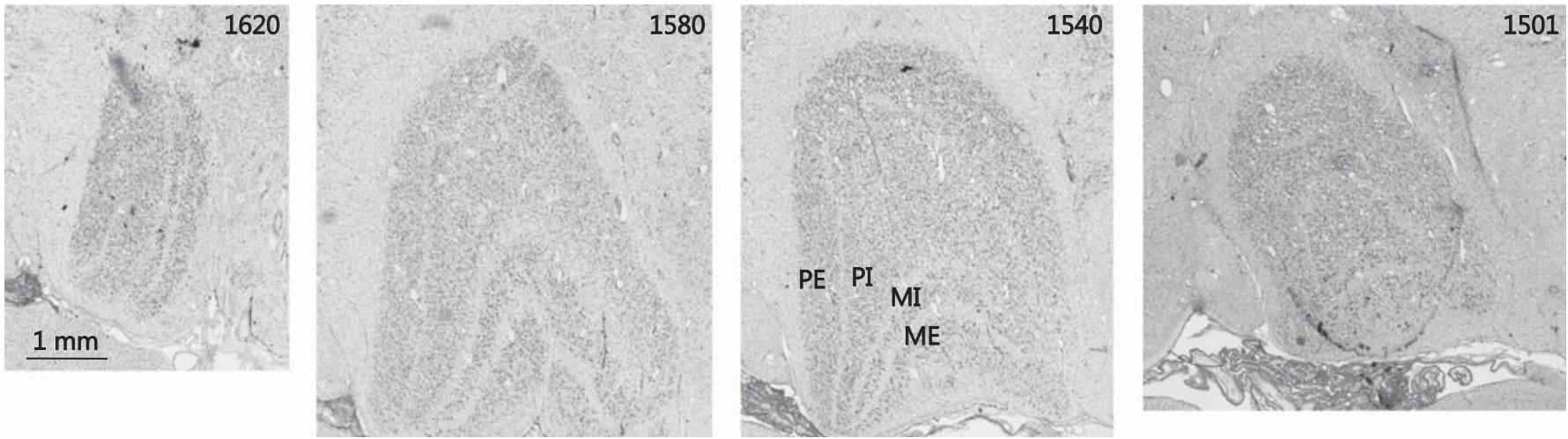

Fig. 5. Coronal sections through right LGN of a red colobus money (Piliocolobus badius). Sections are numbered from rostral to caudal aspect, as indicated below the images. Two magnocellular layers and 4 parvocellular leaflets are labeled in section 1540 .

served within the cercopithecoid superfamily. All cercopithecine species had 4 parvocellular leaflets. The colobines varied: in the Asian clade, the proboscis monkey (Nasalis larvatus) had 4 parvocellular leaflets but the redshanked douc (Pygathrix nemaeus) had 2 parvocellular layers, and in the African clade, the Angolan colobus monkey (Colobus angolensis) had 4 parvocellular leaflets but the red colobus monkey (Piliocolobus badius) had 2 parvocellular layers. 

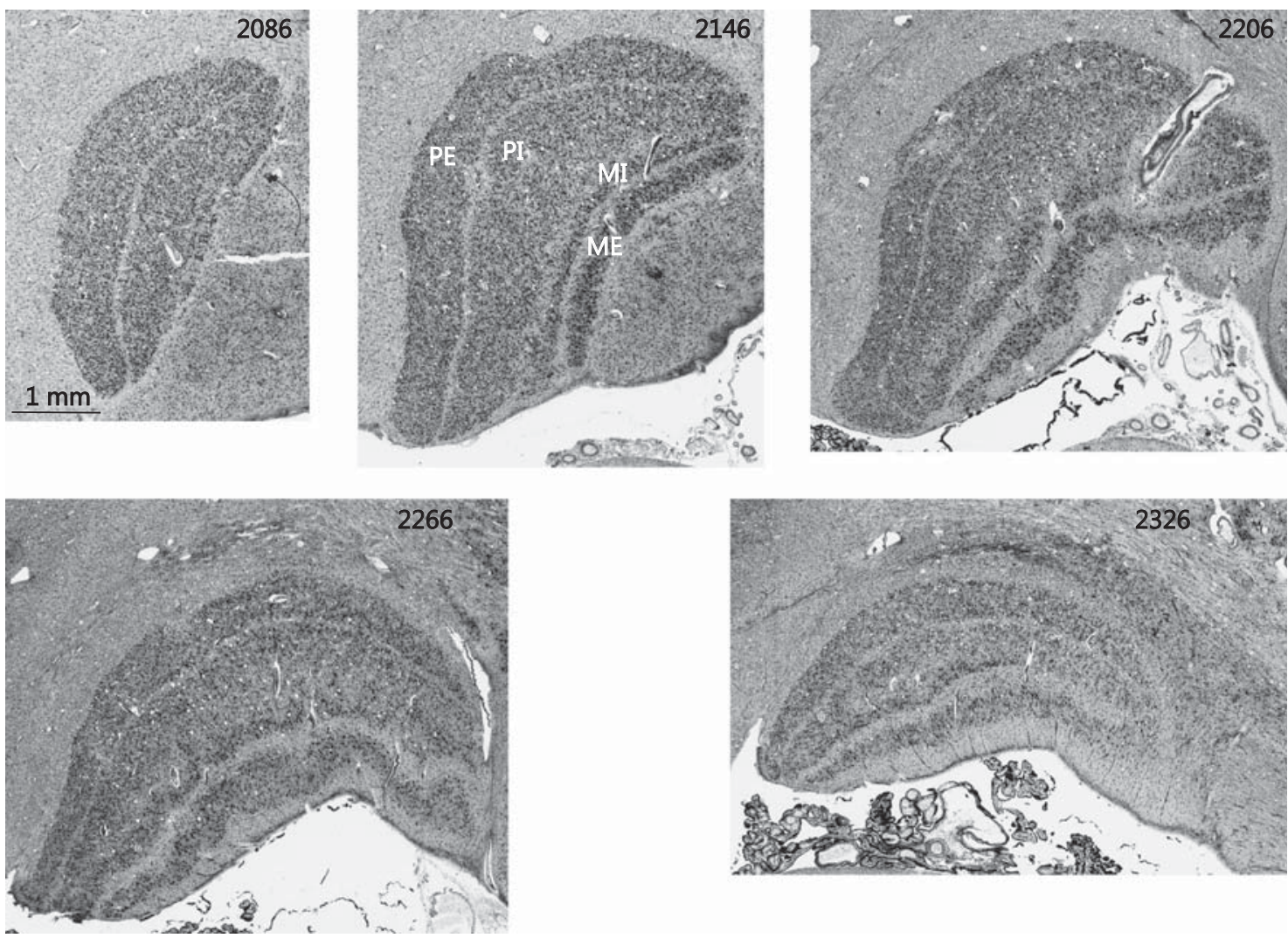

Fig. 6. Coronal sections through left LGN of an orangutan (Pongo pygmaeus). Sections are numbered from caudal to rostral aspect, as indicated below the images. Two magnocellular layers and 2 parvocellular layers are labeled in section 2146 .

\section{Discussion}

This study is the first to document and compare the morphology of the LGN in all living hominoid species, and to include representatives of all catarrhine subfamilies. We found that two main patterns of LGN parvocellular lamination occur within the catarrhines: 2 parvocellular layers in some species and 4 parvocellular leaflets (with occasional subleaflets) in other species. The phylogenetic distribution of these two conditions on the catarrhine consensus phylogeny suggests homoplasy.

Because macaques represent the typical primate model in neuroscience research, neuroanatomical studies rarely venture further than comparisons between macaques and humans. As a result, similarities found between macaques and humans are often assumed to be homologous characters. The lamination of the LGN is a good example of the diversity that exists within the catarrhine clade.

\section{Comparison to Previous Studies of Catarrhine LGN} Lamination

In previous studies, several catarrhine species were demonstrated to have an LGN lamination pattern of 2 parvocellular layers further divided into 4 leaflets. These include humans [Balado and Franke, 1937], chimpanzees [Chacko, 1955b; Tigges et al., 1977], gorillas [Nakagawa et al., 1998] and several cercopithecine monkeys [Kaas et al., 1978].

The only hominoid species previously documented to have an LGN laminar pattern of 2 undivided parvocellular layers were the lar gibbons (Hylobates lar) and the silvery gibbons (Hylobates moloch) [Tigges and Tigges, 1987]. In addition, one other catarrhine species, Piliocolobus badius, was documented as having 2 undivided parvocellular LGN layers in Schulz [1967] (see fig. 5-7), but this rather obscure report has been overlooked and the laminar pattern of the cercopithecines has been generalized to all Old World monkeys, e.g. Kaas and Huerta [1988] and Kaas and colleagues [1978]. 
Fig. 7. Coronal sections through left LGN of 2 different hylobatid species, Müller's gibbon (Hylobates muelleri; a) and siamang (Symphalangus syndactylus; b). Two magnocellular layers and 2 parvocellular layers are labeled in each species.
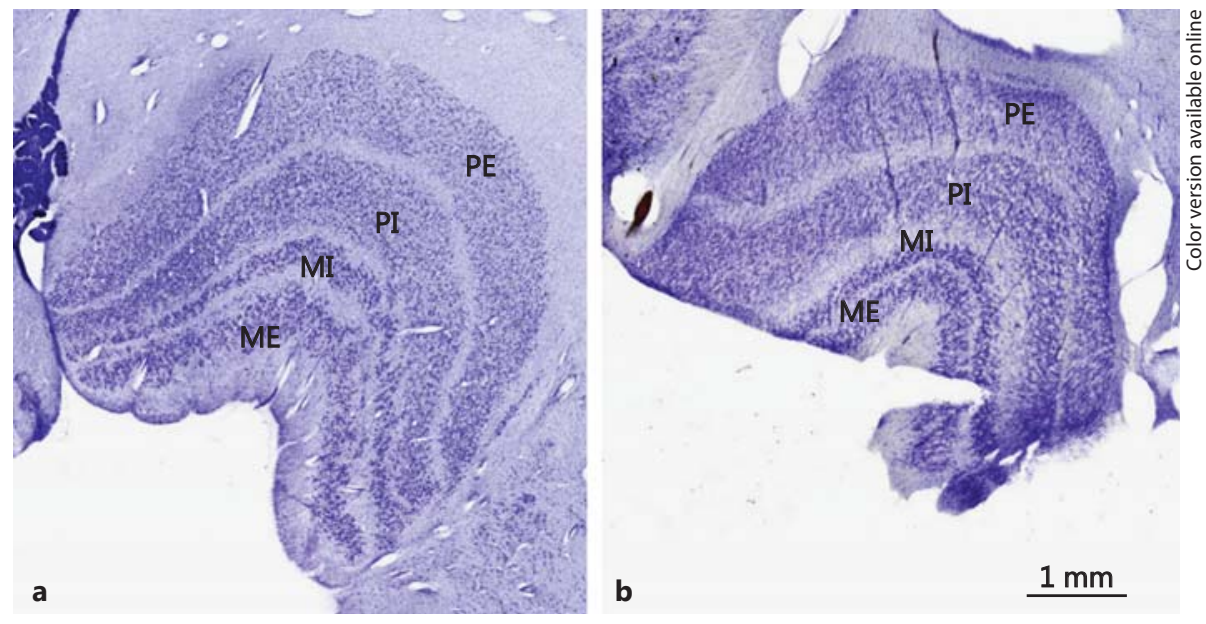

This study adds new information about the laminar pattern of orangutans and siamangs. The orangutan LGN has been previously described as displaying a pattern of 4 parvocellular leaflets and 2 magnocellular layers [Armstrong and Frost, 1988; Balado and Franke, 1937; but see Tigges and Tigges, 1987]. Also, it was stated that siamangs (Symphalangus syndactylus) have 2 parvocellular layers and, inferior to them, 4 magnocellular layers [Kanagasuntheram et al., 1969; fig. 13 therein], but the additional layers may actually be S layers [Kaas et al., 1978]. The discrepancy between these older data and the current observations of only 2 parvocellular layers seems to be due to differences in the identification of layer types (e.g. S layers probably identified as magnocellular layers) and examination of the full rostrocaudal extent of the LGN. However, future studies may also reveal intraspecific differences in LGN lamination not identified here.

In some species, there are reports of individual specimens in which LGN parvocellular layers are comprised of 6 fully developed subleaflets, or in some cases, less developed partial subsidiary lamination. Species for which there have been reports of subleaflets or other subsidiary lamination of the parvocellular layers of the LGN include Homo sapiens [Hickey and Guillery, 1979], Pan paniscus [Tigges et al., 1977], Macaca mulatta [Le Gros Clark and Penman, 1934], Macaca fascicularis [O'Brien et al., 1997], Papio ursinus [Campos-Ortega and Hayhow, 1970], Mandril-lus sphinx [Kaas and Huerta, 1988] and Cercopithecus aethiops [Kanagasuntheram et al., 1969]. This study also found subleaflets in Erythrocebus patas, Cercopithecus mitis and Macaca mulatta. The presence of subleaflets has been considered in so few individuals that fur- ther observations would likely increase its known prevalence, at least in some species. In fact, the high incidence of cases of subleaflets in humans has been indicated as a potential specialization, perhaps due to a general pattern of increased variability that follows an increase in brain size, or due to relaxation of selection pressures which in other species constrain LGN morphology [Hickey and Guillery, 1979].

Although sections stained for cell bodies are sufficient for identifying the parvocellular layers in the LGN of most primates, the possibility of 'hidden layers' can only be ruled out by tracing retinal inputs. Adjacent parvocellular layers receive opposite retinal inputs, as demonstrated by tracing studies. Although in most primate species parvocellular layers are well separated by interlaminar space, there are exceptions in the platyrrhines (New World monkeys). Retinal-projection tracing studies in squirrel and saki monkeys have revealed 4 hidden parvocellular leaflets, despite the fact that these species exhibit a large parvocellular mass that cannot be clearly divided into layers in sections stained for cell bodies [Kaas et al., 1978]. Also, owl monkeys and marmosets appear to have 2 undivided parvocellular layers, but hidden leaflets have been exposed in tracing studies [Kaas et al., 1978]. Although in all other primate species, retinal tracing studies have confirmed observations about parvocellular lamination made on sections stained for cell bodies, it is possible that the degree of lamination is underestimated when based only on cytoarchitectural examination.

Within the catarrhines, observations about LGN lamination patterns have been confirmed using retinal tracers in a variety of cercopithecines [Kaas and Huerta, 1988; 

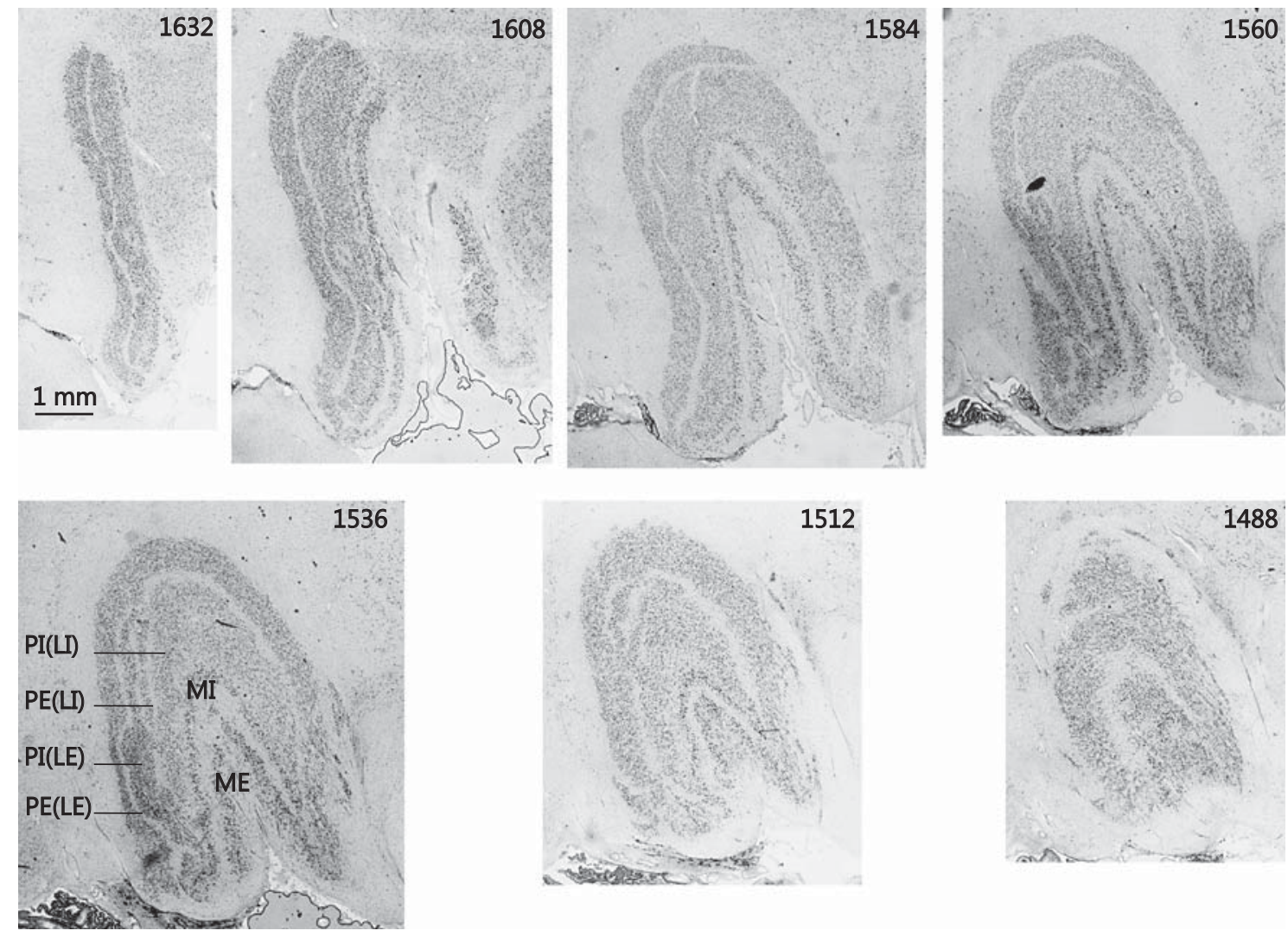

Fig. 8. Coronal sections through right LGN of a proboscis monkey (Nasalis larvatus). Sections are numbered from rostral to caudal aspect, as indicated below the images. Two magnocellular layers and 2 parvocellular layers are labeled in section 1536 .

Kaas et al., 1978]. Studies of retinal inputs to the LGN are rare in hominoids because such investigations require invasive procedures, but two individuals have been studied: one chimpanzee [Tigges et al., 1977] and one gibbon, $\mathrm{Hy}$ lobates [Tigges and Tigges, 1987]. Hidden parvocellular leaflets are not known to occur within catarrhines, although they exist in the platyrrhines and might exist in taxa for which tracing studies have not been performed.

\section{Phylogenetic Implications}

This study has detailed the LGN lamination pattern among catarrhine primate species. However, it is difficult to analyze the evolution of the LGN in catarrhines, because the outgroup, the platyrrhines, have lamination patterns that are hard to fit into character states comparable to those of the catarrhines (see Kaas et al. [1978]). For example, consider Hylobates lar and Macaca mulatta compared to the squirrel monkey (Saimiri sciureus), a New World monkey in which retinal inputs to the LGN have also been investigated. The squirrel money has a large, continuous parvocellular mass comprised of 4 'hidden' parvocellular leaflets. On the one hand, the 4 parvocellular leaflets in Saimiri sciureus resemble the parvocellular lamination of Macaca mulatta. However, the leaflets of squirrel monkeys are not all separated by interlaminar space, differing from both Hylobates lar and Macaca mulatta, and could indicate differences in parvocellular or koniocellular organization. Further research is necessary to accurately identify homologous characters beyond the scope of this study, and thus discern meaningful character states that can be applied to a greater representation of taxa.

Kaas and colleagues [1978] speculated that the last common ancestor of anthropoid primates had an LGN lamination pattern that included 2 undivided parvocellular layers. They suggest that the occurrence of leaflets which are separated by interlaminar space is a primitive catarrhine characteristic, and that the lack of leaflets in 


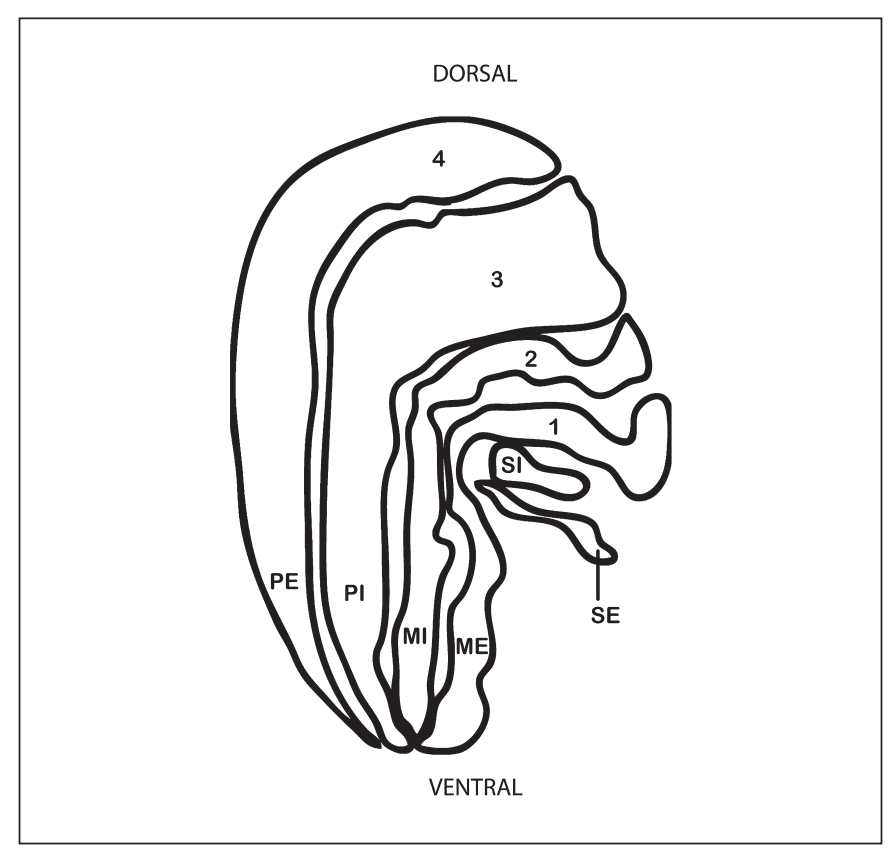

Fig. 9. Schematic diagram showing layers of the LGN in Hylobates lar. Traditional (1-4) nomenclature (left) and nomenclature according to Kaas and colleagues [1978] (right) are shown.

hylobatids is most likely an autapomorphy because it is more parsimonious for leaflets to have been lost once than to have developed independently in hominoids and cercopithecoids. However, they also point out that hylobatids (and, based on this study, colobines and orangutans) have the simplest and most primitive-looking LGN lamination pattern. Although the strepsirrhine primates (galagos, lorises and lemurs) have only 2 parvocellular layers and 2 magnocellular layers, they also exhibit 2 dominant koniocellular layers visible in material stained for cell bodies, and therefore have more elaborately laminated LGNs than those of catarrhines that also lack leaflets. In fact, the only other primates with a similarly simple LGN lamination pattern in material stained for cell bodies are the tarsiers, which also have only 2 magnocellular and 2 parvocellular layers, although a thin konicellular layer is exposed when stained for calbindin [Collins et al., 2005]. Although peculiarities of the tarsier LGN [Le Gros Clark, 1930; McDonald et al., 1993; Rosa et al., 1996; Sereno and Allman, 1991] have long implicated the species' primitiveness among primates, alternatively these could be specializations for vision in low light [Collins et al., 2005].

In the light of the new data presented here, it is equally parsimonious to explain the LGN laminar pattern of

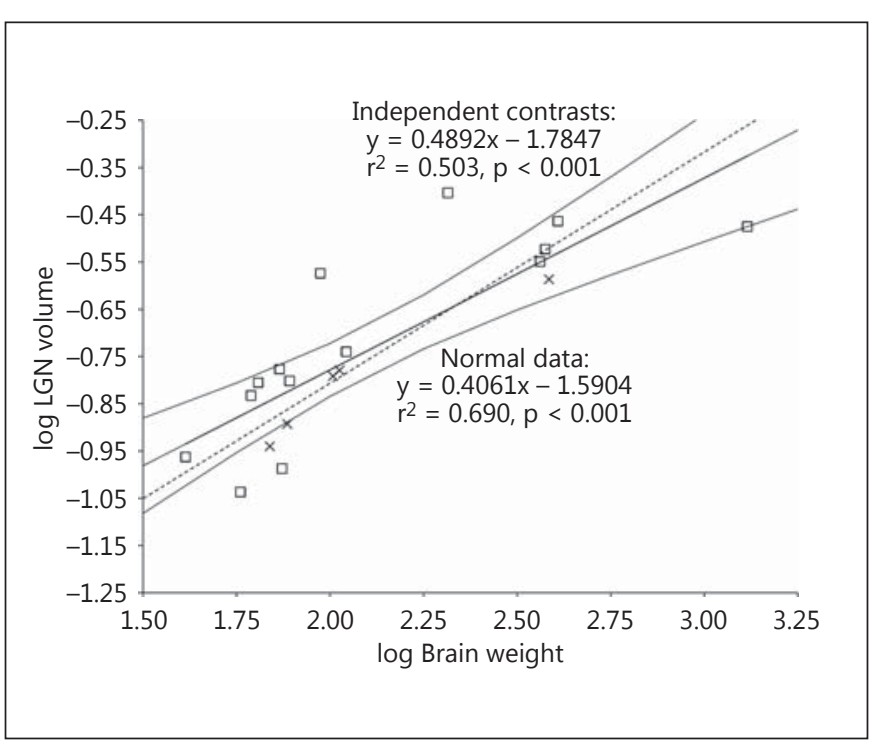

Fig. 10. Regression of LGN volume as a function of brain weight in catarrhines. Least-squares regression lines with upper and lower 95\% confidence intervals (solid lines) and PIC least-squares regressions (dotted lines) are shown. Species mean values are plotted for species with 4 parvocellular leaflets (open squares) and 2 undivided parvocellular layers (crosses).

hylobatids as a retention of the primitive catarrhine pattern or as the ancestral condition of the hominoid clade, retained in hylobatids and orangutans but lost in the African hominoids (fig. 3). This finding is not insignificant. Macaques are used in translational research as a model to better understand the function of the human LGN. The fact that the laminar patterns of these two taxa might not be derived from a common ancestor means that extrapolations from macaques to humans of LGN laminar function should be made with caution. The current finding of homoplasy in LGN lamination pattern lends support to the possibility that too few character states have been identified. Further research may produce more detailed descriptions of the LGN lamination pattern of catarrhines, which take into consideration additional details about neuronal populations.

\section{Functional Implications}

It is possible that hylobatids, orangutans and some colobines possess the primitive LGN lamination pattern and that greater parvocellular interdigitation appeared independently in African apes, cercopithecines and other colobines. The alternative hypothesis, that LGN parvocellular lamination was reduced in these species, would have to be explained by relaxation of selective pressures, 
which might have led to a loss of parvocellular inputs related to color vision. If an LGN with 2 undivided parvocellular layers were the primitive condition, why would a pattern of 4 parvocellular leaflets develop in the African ape and human clade, the cercopithecine clade and in some colobine species?

While the functional significance of having leaflets is not very well understood [Campos-Ortega and Hayhow, 1970; Kaas and Huerta, 1988; Kaas et al., 1978], available evidence suggests that lamination and the presence of leaflets might be related to the thickening of the parvocellular mass [Kaas et al., 1972, 1978]. A reduction in the thickness of parvocellular layers is achieved by splitting each thick parvocellular layer into 2 thinner leaflets. Because leaflets alternate with regard to retinal input, this would shorten the distance between neurons receiving inputs from different eyes, and thus facilitate interocular interactions [Kaas et al., 1978]. Thus, in species with relatively increased parvocellular mass related to enhanced processing capacities for color vision, the presence of leaflets may exist as a mechanism to retain optimal interocular interaction. Unfortunately, there remains a dearth of evidence for this hypothesis. Among mammals, obvious lamination of the LGN occurs not only in primates, but also in carnivores. In some carnivores, the LGN layers are also subdivided into leaflets. However, unlike in primates, leaflets do not alternate with regard to retinal input [Sanderson, 1974]; they are, therefore, unlikely to facilitate interocular interactions.

The amount of LGN tissue delegated to parvocellular and magnocellular inputs varies within primate species, and is related to activity pattern and ecology. Diurnal primates have a proportionally larger parvocellular part of the LGN than do nocturnal primates [Hassler, 1966], presumably because diurnal species rely more on information of the parvocellular pathway, such as color vision. Similarly, it has been hypothesized that increased lamination through the presence of leaflets may be related to improved color vision [Tigges and Tigges, 1987].

Although it was previously suggested that blue-sensitive cells were most concentrated in the two most ventral parvocellular cells in the macaque LGN [Schiller and Malpeli, 1978], it is now clear that blue-sensitive cells are predominantly located either in the koniocellular layers or in the 'koniocellular bridges' that fully or partially span the parvocellular layers [Roy et al., 2009]. There have also been other indications that parvocellular layers differ according to optical specificity. The ventral-most pair of parvocellular leaflets also has cells that respond mostly off-center, whereas the dorsal parvocellular leaflets respond mostly on-center [Schiller and Malpeli, 1978]. This is interesting because the pairing of function is patterned by location and not by retinal projection, and so functional groups cross parvocellular layers, such that the LI of PE and PI group together and their LE group together. Central vision is represented in the segment of the LGN having 4 parvocellular leaflets in macaques [Malpeli and Baker, 1975]; therefore, the additional layers may reflect an increased dedication to central vision.

Prior to this study, it had only been clear that hylobatids departed from the typical catarrhine LGN lamination pattern, so this taxon has been contrasted against other catarrhine species in this regard. In fact, because it remains the only catarrhine species for which tracing studies confirm 2 undivided parvocellular layers, it remains possible that the hylobatid laminar pattern is unique among catarrhines. Tigges and Tigges [1987] relate the LGN lamination of gibbons to several aspects of behavior and physiology. It has also been suggested that gibbons are missing the 2 ventral parvocellular layers, which are important in color vision due to the predominance of blue-sensitive cells [Schiller and Malpeli, 1978]. In support of this hypothesis, there is evidence of poor blue discrimination in gibbons [Tigges, 1963] and a higher rod-to-cone ratio in gibbons than in rhesus macaques [Polyak, 1957; Rohen, 1962].

Also, it has been suggested that the relatively decreased lamination of the gibbon LGN probably does not have a negative effect on other visual functions such as motion detection [Tigges and Tigges, 1987]. Gibbons may have neural specializations for motion detection because they are arboreal brachiators which move quickly in a complex 3-dimensional environment. Changes in the parvocellular layers are not expected to have a negative effect on motion detection, particularly because it is the magnocellular layers that are the primary conduit of this category of visual information.

Finally, it is interesting to consider how the difference in LGN lamination may relate to the behavioral differences among species of cercopithecoid monkeys. The parvocellular layers of the LGN are involved in color vision. It has been hypothesized that trichromatic color vision, which occurs in all catarrhine species, evolved as a result of either frugivorous [Mollon, 1989; Sumner and Mollon, 2000] or folivorous [Dominy and Lucas, 2001; Lucas et al., 1998] behavior. In fact, the cercopithecoid species with 4 parvocellular leaflets include both primarily frugivorous cercopithecines and some primarily folivorous colobines. Also, it has been argued recently that all catarrhines, including colobines and gibbons [contra Tigges and Tigges, 1987] are identical in terms of spectral sensitivity [Deegan and Jacobs, 2001; Jacobs and Deegan, 
1999]. Therefore, any potential difference in color vision would have to be at a postretinal level.

The traditional notion that the LGN is a simple relay nucleus for retinal inputs on their way to the cerebral cortex has been disputed by studies which have shown that the human LGN receives inputs from the striate cortex, the thalamic reticular nucleus and the brainstem; in fact, only $10 \%$ of its inputs originate from the retina [Kastner et al., 2006]. Therefore, the LGN is in a strategic position to serve as 'gatekeeper' which modulates attention to visual stimuli.

Further, in macaques, the LGN projects not only to primary visual area, but also to extrastriate areas. In macaques, V2 receives a direct LGN input, mostly from the interlaminar zones and S layers [Bullier and Kennedy, 1983], and prestriate areas receiving LGN inputs probably also include V3 and V4 [Benevento and Standage, 1982; Fries, 1981; Yukie and Iwai, 1981]. More recently it was confirmed that MT, involved in motion detection, also receives a direct input from LGN neurons located primarily in interlaminar zones and from others scattered throughout the parvocellular and magnocellular laminae [Sincich et al., 2004]. This, taken together with evidence of direct inputs from the superior colliculus to interlaminar layers of the LGN in macaques, suggests a disynaptic tectogeniculocortical koniocellular visual pathway, which has been more fully documented in New World monkey species [Stepniewska et al., 1999, 2000]. However, only some extrastriate-projecting LGN neurons immunostained for the koniocellular marker aCAMKII indicate heterogeneity among the interlaminar neurons [Rodman et al., 2001; Sincich et al., 2004]. The conventional functional role of LGN pathways has been further questioned by the discovery of a disynaptic pathway in which MT receives a parvocellular input after a relay in primary visual cortex [Nassi et al., 2006].

These new findings suggest that the role of the LGN is much more complicated than previously thought. It is interesting to consider that LGN lamination may be related to higher-level processing of, for example, parvocellular inputs. In such an example, it is possible that (1) the LGN acts as a modulator of parvocellular information, e.g. a filter of information related to trichromatic color vision and/or (2) there may be taxonomic differences in the existence of intercalated neuronal populations which may even have direct inputs to higher-order, more functionally specific visual cortical areas.

\section{Methodological Considerations}

The foregoing conclusions should be considered preliminary because of the methodological limitations of this study. Importantly, it was not feasible to reveal the source of retinal input to each LGN layer, and thereby reveal possible 'hidden' layers. Because hidden lamination at the level of leaflets or subleaflets has not been observed in catarrhines thus far, the existence of hidden layers in the catarrhines would seem unlikely, but cannot be ruled out. Therefore, in species for which retinal tracings to the LGN have not been studied, the number of leaflets should be taken to be a minimum number. Perhaps the findings here will be confirmed through the use of noninvasive methods such as diffusion tensor MRI to study LGN structure and connections in ape species.

Although the samples used in this study are relatively small, it is important to note that they are a significant improvement on previous studies of the LGN in hominoids. Although within-species variation may occur at the level of subsidiary lamination such as subleaflets, at the level of layers and leaflets LGN lamination seems to be standard within species, making it unlikely that larger samples would have any effect on the general findings made here.

In summary, the increased lamination of parvocellular layers, a parallel occurrence in the African hominoids, cercopithecines and some colobines, may be functionally relevant. An increased number or better differentiation of parvocellular layers with leaflets may be related to color vision or to improved perception of central (vs. peripheral) vision. Alternatively, increased lamination may simply provide more interlaminar space for neuronal populations that do not participate in the parvocellular and magnocellular geniculocortical pathways, but rather have direct extrastriate inputs, e.g. those related to motion detection.

\section{Acknowledgements}

We are grateful to Drs. Bernard Wood, Ralph Holloway, Peter Lucas and Brian Richmond for comments on earlier versions of the manuscript. Dr. Katerina Semendeferi was instrumental in establishing the Zilles ape brain collection used in this study. Dr. Joseph Erwin facilitated access to great ape brain specimens. The Yerkes Primate Center also provided brains. This work was supported by the National Science Foundation (BCS-9987590, BCS0453005, BCS-0515484, BCS-0549117, BCS-0827531 and DGE0801634), the Fundação para a Ciência e a Tecnologia (SFRH/ BPD/43518/2008), the National Institutes of Health (NS42867) and the James S. McDonnell Foundation (22002078 and 220020293). 


\section{References}

-Albright TD, Desimone R, Gross CG (1984): Columnar organization of directionally selective cells in visual area MT of the macaque. J Neurophysiol 51:16-31.

Armstrong E (1979): Quantitative comparison of the hominoid thalamus. I. Specific sensory relay nuclei. Am J Phys Anthropol 51:365-382.

Armstrong E, Frost GT (1988): The diencephalon: a comparative review; in Schwartz JH (ed): Orang-Utan Biology. Oxford, Oxford University Press, pp 177-188.

Aarnold C, Matthews LJ, Nunn CL (2010): The 10kTrees Website: a new online resource for primate phylogeny. Evol Anthropol 19:114118.

Balado M, Franke E (1937): Das Corpus Geniculatum Externum. Berlin, J. Springer.

Benevento LA, Standage GP (1982): Demonstration of lack of dorsal lateral geniculate nucleus input to extrastriate areas MT and Visual 2 in the macaque monkey. Brain Res 252:161-166.

Bullier J, Kennedy H (1983): Projection of the lateral geniculate nucleus onto cortical area V2 in the macaque monkey. Exp Brain Res 53: 168-172.

Campos-Ortega JA, Hayhow WR (1970): A new lamination pattern in the lateral geniculate nucleus of primates. Brain Res 20:335-339.

- Casagrande VA, Yazar F, Jones KD, Ding Y (2007): The morphology of the koniocellular axon pathway in the macaque monkey. Cereb Cortex 17:2334-2345.

Chacko L (1948): The laminar pattern of the lateral geniculate body in the primate. J Neurol Neurosurg Psychiatry 11:211-224.

Chacko L (1954): The lateral geniculate body in the New World monkeys. J Anat Soc India 3: 62-74.

Chacko L (1955a): The lateral geniculate body in gibbon (Hylobates hoolock). J Anat Soc India 4:69-81.

Chacko L (1955b): The lateral geniculate body of the chimpanzee. J Anat Soc India 4:10-13.

Chacko LW (1949): A preliminary study of the distribution of cell size in the lateral geniculate body. J Anat 83:254-266, 253.

Collins CE, Hendrickson A, Kaas JH (2005): Overview of the visual system of Tarsius. Anat Rec 287:1013-1025.

Dacey DM, Peterson BB, Robinson FR, Gamlin PD (2003): Fireworks in the primate retina: in vitro photodynamics reveals diverse LGNprojecting ganglion cell types. Neuron 37:1527.

Deegan JF, Jacobs GH (2001): Spectral sensitivity of gibbons: implications for photopigments and color vision. Folia Primatol 72:26-29.

De Valois RL, Smith CJ, Kitai ST, Karoly AJ (1958): Response of single cells in monkey lateral geniculate nucleus to monochromatic light. Science 127:238-239.

-DeYoe EA, Felleman DJ, Van Essen DC, McClendon E (1994): Multiple processing streams in occipitotemporal visual cortex. Nature 371: 151-154.
DeYoe EA, Hockfield S, Garren H, Van Essen DC (1990): Antibody labeling of functional subdivisions in visual cortex: Cat-301 immunoreactivity in striate and extrastriate cortex of the macaque monkey. Vis Neurosci 5:67-81.

DeYoe EA, Van Essen DC (1988): Concurrent processing streams in monkey visual cortex. Trends Neurosci 11:219-226.

Dominy NJ, Lucas PW (2001): Ecological importance of trichromatic vision to primates. $\mathrm{Na}$ ture 410:363-366.

Erwin E, Baker FH, Busen WF, Malpeli JG (1999): Relationship between laminar topology and retinotopy in the rhesus lateral geniculate nucleus: results from a functional atlas. J Comp Neurol 407:92-102.

Felleman DJ, Van Essen DC (1987): Receptive field properties of neurons in area V3 of macaque monkey extrastriate cortex. J Neurophysiol 57:889-920.

Fries W (1981): The projection from the lateral geniculate nucleus to the prestriate cortex of the macaque monkey. Proc R Soc Lond B Biol Sci 213:73-80.

Fukuda K, Saito N, Yamamoto M, Tanaka C (1994): Immunocytochemical localization of the alpha-, beta I-, beta II- and gamma-subspecies of protein kinase $\mathrm{C}$ in the monkey visual pathway. Brain Res 658:155-162.

Gallyas F (1971): A principle for silver staining of tissue elements by physical development. Acta Morphol Acad Sci Hung 19:57-71.

Goodchild AK, Martin PR (1998): The distribution of calcium-binding proteins in the lateral geniculate nucleus and visual cortex of a New World monkey, the marmoset, Callithrix jacchus. Vis Neurosci 15:625-642.

Hassler R (1966): Comparative anatomy in day and night active primates; in Hassler R, Stephan H (eds): Evolution of the Forebrain. Stuttgart, Thieme, pp 419-434.

Hendry SH, Reid RC (2000): The koniocellular pathway in primate vision. Annu Rev Neurosci 23:127-153.

Hendry SH, Yoshioka T (1994): A neurochemically distinct third channel in the macaque dorsal lateral geniculate nucleus. Science 264: 575-577.

Hickey TL, Guillery RW (1979): Variability of laminar patterns in the human lateral geniculate nucleus. J Comp Neurol 183:221-246.

Huberman AD, Chapman B (2007): Evolution and development of eye-specific layers in the lateral geniculate nucleus; in Kaas $\mathrm{JH}$ (ed): Evolution of Nervous Systems, vol 3: Mammals. Oxford, Academic Press, pp 319-328.

Jacobs GH, Deegan JF (1999): Uniformity of colour vision in Old World monkeys. P Roy Soc Lond B Bio 266:2023-2028.

Jones EG, Hendry SH (1989): Differential calcium binding protein immunoreactivity distinguishes classes of relay neurons in monkey thalamic nuclei. Eur J Neurosci 1:222-246.
Kaas JH, Guillery RW, Allman JM (1972): Some principles of organization in the dorsal lateral geniculate nucleus. Brain Behav Evol 6:253299.

- Kaas JH, Huerta MF, Weber JT, Harting JK (1978): Patterns of retinal terminations and laminar organization of the lateral geniculate nucleus of primates. J Comp Neurol 182:517553

Kaas JH, Huerta MF (1988): The subcortical visual system of primates; in Stelis HD, Erwin J (eds): Comparative Primate Biology, vol 4: Neurosciences. New York, Liss, pp 327-391.

Kanagasuntheram R, Krishnamurti A, Wong WC (1969): Observations on the lamination of the lateral geniculate body in some primates. Brain Res 14:623-631.

Kastner S, Schneider KA, Wunderlich K (2006): Beyond a relay nucleus: neuroimaging views on the human LGN. Prog Brain Res 155:125143.

Le Gros Clark WE (1930): The thalamus of Tarsius. J Anat 64:371-414.

Le Gros Clark WE (1941a): The lateral geniculate body in the platyrrhine monkeys. J Anat 76: 131-140.

Le Gros Clark WE (1941b): The laminar organization and cell content of the lateral geniculate body in the monkey. J Anat 75:419-433.

Le Gros Clark WE (1949): The laminar pattern of the lateral geniculate nucleus considered in relation to colour vision. Doc Ophthalmol 3: 57-64.

Le Gros Clark WE, Penman GG (1934): The projection of the retina in the lateral geniculate body. Proc R Soc Lond B 114:291-313.

- Leventhal AG, Rodieck RW, Dreher B (1981): Retinal ganglion cell classes in the Old World monkey: morphology and central projections. Science 213:1139-1142.

- Lucas PW, Darvell BW, Lee PK, Yuen TD, Choong MF (1998): Colour cues for leaf food selection by long-tailed macaques (Macaca fascicularis) with a new suggestion for the evolution of trichromatic colour vision. Folia Primatol 69:139-152.

Lueck CJ, Zeki S, Friston KJ, Deiber MP, Cope P, Cunningham VJ, Lammertsma AA, Kennard C, Frackowiak RS (1989): The colour centre in the cerebral cortex of man. Nature 340:386389.

Malpeli JG, Baker FH (1975): The representation of the visual field in the lateral geniculate nucleus of Macaca mulatta. J Comp Neurol 161: 569-594.

Malpeli JG, Lee D, Baker FH (1996): Laminar and retinotopic organization of the macaque lateral geniculate nucleus: magnocellular and parvocellular magnification functions. J Comp Neurol 375:363-377.

Martin PR, White AJ, Goodchild AK, Wilder HD, Sefton AE (1997): Evidence that blue-on cells are part of the third geniculocortical pathway in primates. Eur J Neurosci 9:1536-1541. 
-McDonald CT, McGuinness ER, Allman JM (1993): Laminar organization of acetylcholinesterase and cytochrome oxidase in the lateral geniculate nucleus of prosimians. Neuroscience 54:1091-1101.

McKeefry DJ, Zeki S (1997): The position and topography of the human colour centre as revealed by functional magnetic resonance imaging. Brain 120:2229-2242.

Merker B (1983): Silver staining of cell bodies by means of physical development. J Neurosci Methods 9:235-241.

Mollon JD (1989): 'Tho' she kneel'd in that place where they grew ...' The uses and origins of primate colour vision. J Exp Biol 146:21-38.

-Nakagawa S, Tigges J, Tigges M (1998): Laminar organization of the lateral geniculate nucleus of the gorilla. Folia Primatol 69:377-380.

Nassi JJ, Lyon DC, Callaway EM (2006): The parvocellular LGN provides a robust disynaptic input to the visual motion area MT. Neuron 50:319-327.

O’Brien BJ, Abel PL, Olavarria JF (1997): A morphological anomaly of the dorsal lateral geniculate nucleus in Macaca fascicularis. Cell Tissue Res 289:11-16.

Polyak S (1957): The Vertebrate Visual System. Chicago, Univ. of Chicago Press.

- Regan BC, Julliot C, Simmen B, Vienot F, CharlesDominique P, Mollon JD (2001): Fruits, foliage and the evolution of primate colour vision. Philos Trans R Soc Lond B Biol Sci 356: 229-283.

Rodiek RW (1988): The primate retina; in Stelis HD, Erwin J (eds): Comparative Primate Biology, vol 4: Neurosciences. New York, Liss, pp 203-278.

Rodman HR, Sorenson KM, Shim AJ, Hexter DP (2001): Calbindin immunoreactivity in the geniculo-extrastriate system of the macaque: implications for heterogeneity in the koniocellular pathway and recovery from cortical damage. J Comp Neurol 431:168-181.
Rohen J (1962): Sehorgan; in Hofer H, Schultz A, Starck D (eds): Primatologia: Handbuch der Primatenkunde. Basel, Karger, pp 1-210.

- Rosa MGP, Pettigrew JD, Cooper HM (1996): Unusual pattern of retinogeniculate projections in the controversial primate Tarsius. Brain Behav Evol 48:121-129.

Roy S, Jayakumar J, Martin PR, Dreher B, Saalmann YB, Hu D, Vidyasagar TR (2009): Segregation of short-wavelength-sensitive $(\mathrm{S})$ cone signals in the macaque dorsal lateral geniculate nucleus. Eur J Neurosci 30:15171526.

Saalmann YB, Kastner S (2011): Cognitive and perceptualfunctions of the visual thalamus. Neuron 71:209-223.

Sanderson KJ (1974): Lamination of the dorsal lateral geniculate nucleus in carnivores of the weasel (Mustelidae), raccoon (Procyonidae) and fox (Canidae) families. J Comp Neurol 153:239-266.

-Schiller PH, Malpeli JG (1978): Functional specificity of lateral geniculate nucleus laminae of the rhesus monkey. J Neurophysiol 41:788797.

Schulz H-D (1967): Metrische Untersuchungen an den Schichten des Corpus geniculatum laterale tag- und nachtaktiver Primaten; in: Hohe Medizinische Fakultät. Frankfurt a. M., Johann Wolfgang Goethe-Universität.

Sereno M, Allman JM (1991): Cortical visual areas in mammals; in Leventhal AG (ed): The Neural Basis of Visual Function. London, Macmillan, pp 160-172.

Sincich LC, Park KF, Wohlgemuth MJ, Horton JC (2004): Bypassing V1: a direct geniculate input to area MT. Nat Neurosci 7:1123-1128.

Solnitzky O, Harman P (1943): The lateral geniculate complex in the spider monkey, Ateles ater. Yale J Biol Med 15:615-639.

Stephan H, Frahm H, Baron G (1981): New and revised data on volumes of brain structures in insectivores and primates. Folia Primatol 35: $1-29$.
Stepniewska I, Qi H-X, Kaas JH (1999): Do superior colliculus projection zones in the inferior pulvinar project to MT in primates? Eur J Neurosci 11:469-480.

Stepniewska I, Ql HX, Kaas JH (2000): Projections of the superior colliculus to subdivisions of the inferior pulvinar in New World and Old World monkeys. Vis Neurosci 17:529_ 549.

Sumner P, Mollon JD (2000): Catarrhine photopigments are optimized for detecting targets against a foliage background. J Exp Biol 203: 1963-1986.

Tigges J (1963): On colour vision in gibbon and orang-utan. Folia Primatol (Basel) 1:188-198.

- Tigges J, Bos J, Tigges M (1977): An autoradiographic investigation of the subcortical visual system in chimpanzee. J Comp Neurol 172: 367-380.

Tigges J, Tigges M (1987): Termination of retinofugal fibers and lamination pattern in the lateral geniculate nucleus of the gibbon. Folia Primatol 48:186-194.

Tootell RB, Mendola JD, Hadjikhani NK, Ledden PJ, Liu AK, Reppas JB, Sereno MI, Dale AM (1997): Functional analysis of V3A and related areas in human visual cortex. J Neurosci 17:7060-7078.

- Van Essen DC, Anderson CH, Felleman DJ (1992): Information processing in the primate visual system: an integrated systems perspective. Science 255:419-423.

-Yoshioka T, Hendry SH (1995): Compartmental organization of layer IVA in human primary visual cortex. J Comp Neurol 359:213-220.

-Yukie M, Iwai E (1981): Direct projection from the dorsal lateral geniculate nucleus to the prestriate cortex in macaque monkeys. J Comp Neurol 201:81-97.

Zeki SM (2004): Improbable areas in color vision; in Chalupa LM, Werner JS (eds): The Visual Neurosciences, vol 2. Cambridge, MIT Press, pp 1029-1039. 